\title{
Galvanic Corrosion of a Zn/steel Couple in Aqueous NaCl
}

\author{
Eiji TADA $^{1) *}$ and Hiroyuki KANEKO ${ }^{21}$ \\ 1) Department of Materials Science and Engineering, Graduate School of Engineering and Resource Science, Akita University, \\ 1-1 Tegata Gakuen-cho, Akita, 010-8502 Japan. E-mail: tada@ipc.akita-u.ac.jp \\ 2) Professor Emeritus, Akita University, 1- \\ 1 Tegata Gakuen-cho, Akita, 010-8502 Japan.
}

(Received on April 5, 2011; accepted on August 17, 2011)

\begin{abstract}
Galvanic corrosion of a model $\mathrm{Zn}$ /steel couple was investigated in aqueous $\mathrm{NaCl}$ solutions by measuring open circuit potentials (OCPs), potential and current distributions, and galvanic currents. The OCP transient of the $\mathrm{Zn} /$ steel couple was divided into two stages. The first stage consisted of sacrificial dissolution of zinc. At low concentrations of $\mathrm{NaCl}\left(0.01 \mathrm{~mol} / \mathrm{dm}^{3}\right)$, the cathodic reaction on the couple surface was an oxygen reduction reaction (ORR). With increasing concentrations of $\mathrm{NaCl}$, the cathodic reaction at the steel surface changed from an ORR to the combination of an ORR and hydrogen evolution reaction (HER). In addition, the precipitation morphology of zinc corrosion products differed as a function of $\mathrm{NaCl}$ concentration, suggesting that the $\mathrm{pH}$ distribution on the couple surface depended on the relationship between the cathodic reactions and the hydrolysis of $\mathrm{Zn}^{2+}$. Furthermore, the findings demonstrated that both the ORR and HER were inhibited at the steel underlying precipitated zinc corrosion products. The second stage consisted of steel corrosion. The location of the onset of steel corrosion was related to the $\mathrm{pH}$ distribution just prior to the extinction of the galvanic action of zinc.
\end{abstract}

KEY WORDS: zinc; corrosion; galvanic corrosion; sacrificial anode; electrochemical; corrosion product; SVET.

\section{Introduction}

Galvanized steels are used widely in automobiles, household appliances, and construction because of their corrosion-resistant characteristics. ${ }^{1)}$ The high corrosion resistance of galvanized steels is attributed to the slow kinetics of zinc dissolution, the sacrificial dissolution of zinc to prevent steel corrosion, and the barrier effect of zinc corrosion products. ${ }^{2-4)}$ The latter factor in particular seems to inhibit the corrosion of underlying steels. For example, according to Fujita et $a l .,{ }^{5)}$ the precipitation of zinc corrosion products on galvanized steel sheets with $120 \mathrm{~g} / \mathrm{m}^{2}$ of one side coating weight accounts for $45 \%$ of the corrosion-resistant lifetime prior to the onset of steel corrosion. Therefore, clarifying the inhibition mechanism of zinc corrosion products during the corrosion of galvanized steels is important, which implies that the formation of zinc corrosion products must first be elucidated.

In previous papers, ${ }^{6-8)}$ we described the spatial distributions of $\mathrm{H}^{+}\left(\mathrm{OH}^{-}\right)^{6)}$ and dissolved $\mathrm{Zn}^{2+}{ }^{7,8)}$ during the galvanic corrosion of a model $\mathrm{Zn} /$ steel couple immersed in 0.01 $\mathrm{mol} / \mathrm{dm}^{3} \mathrm{NaCl}$ to investigate the formation of zinc corrosion products. The formation process of zinc corrosion products is associated with the concentration fields of $\mathrm{Zn}^{2+}$ and $\mathrm{OH}^{-}$ developed during galvanic corrosion. Zinc corrosion products were not deposited in the immediate vicinity of the zinc, but rather a certain distance away. ${ }^{6)}$ The morphology of the zinc corrosion products was in good agreement with the $\mathrm{pH}$ and $\left[\mathrm{Zn}^{2+}\right]$ distributions at the couple surface. These ionic distributions were developed from the combination of electrochemical reactions at local anodes and cathodes on the couple and subsequent chemical reactions such as the hydrolysis of $\mathrm{Zn}^{2+}$. Therefore, the formation of zinc corrosion products should be correlated with local electrochemical and chemical reactions during galvanic corrosion.

This paper describes the potential and current distributions of a $\mathrm{Zn} /$ steel couple immersed in $\mathrm{NaCl}$ solutions and reveals details of local electrochemical and chemical reactions that take place during galvanic corrosion of the couple. The formation of zinc corrosion products are discussed from the perspective of electrochemical reactions taking place on the couple. In addition, the effects of salt concentration on the formation of zinc corrosion products are discussed.

\section{Experimental Procedures}

\subsection{Zn/steel Couples}

Figure 1 shows schematic diagrams of the $\mathrm{Zn} /$ steel couples used throughout this study to investigate galvanic corrosion. Type A in Fig. 1 depicts a coplanar couple used for measuring corrosion potentials and potential distributions. Type B is a concentric couple applied in measurements of current distribution using a scanning vibrating electrode technique (SVET). Type C is another coplanar couple composed of four steel coupons with one of the four being coated with zinc. In this couple, the zinc-coated steel coupon and the remaining three steel coupons are separated from each other by $200-\mu \mathrm{m}$ gaps. Type $\mathrm{C}$ was used in measurements of galvanic current distribution during corrosion in test solutions. 
(a) Type A

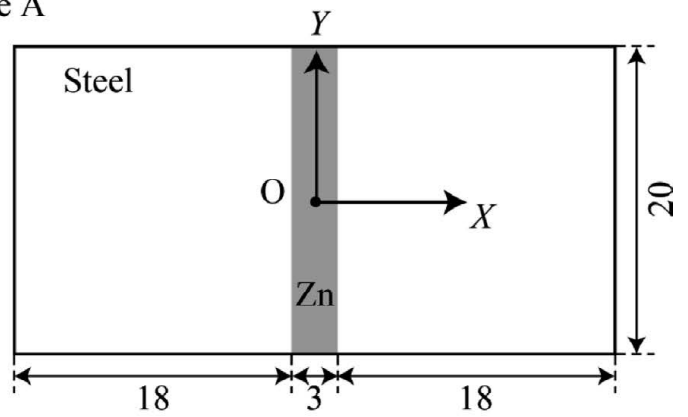

(b) Type B

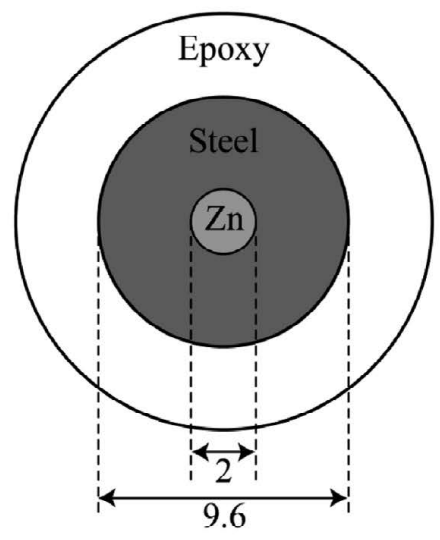

(c) Type $\mathrm{C}$

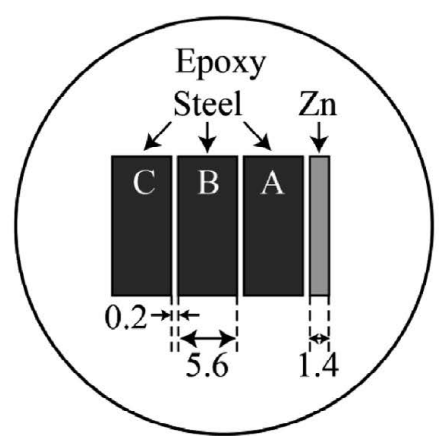

Fig. 1. Three kinds of couples used for galvanic corrosion experiments (unit: $\mathrm{mm}$ ).

All of the $\mathrm{Zn} / \mathrm{steel}$ couples described above were composed of SM400B mild steel coupons (chemical composition: $0.11 \mathrm{wt} \% \mathrm{C}, 0.19 \mathrm{wt} \% \mathrm{Si}, 0.56 \mathrm{wt} \% \mathrm{Mn}, 0.008 \mathrm{wt} \%$ $\mathrm{P}, 0.012 \mathrm{wt} \% \mathrm{~S}$, and the balance $\mathrm{Fe}$ ). The zinc layer on the $\mathrm{Zn} /$ steel couples was electroplated from a mixture of 0.88 $\mathrm{mol} / \mathrm{dm}^{3} \mathrm{ZnCl}_{2}$ and $3.37 \mathrm{~mol} / \mathrm{dm}^{3} \mathrm{NH}_{4} \mathrm{Cl}$ at a constant current density of $-45 \mathrm{mAcm}^{-2}$. Before electroplating, the steel coupons were successively polished up to $\# 2000$ grit with waterproof $\mathrm{SiC}$ sandpaper and then rinsed ultrasonically with ethanol and distilled water. In all cases, the thickness of the zinc layer was aimed at $3 \mu \mathrm{m}$, assuming that the current efficiency for electroplating of zinc was $100 \%$. The area ratios of the zinc layer and the remaining steel surfaces were 1:12, 1:22, and 1:12 for Types A, B, and C, respectively. After electroplating, $\mathrm{Zn} /$ steel couples were rinsed successively with ethanol and distilled water and stored in a desiccator prior to corrosion experiments.

\subsection{Test Solutions}

Aqueous $\mathrm{NaCl}$ solutions were prepared using distilled water and analytical grade chemicals to concentrations from
0.01 to $1 \mathrm{~mol} / \mathrm{dm}^{3}$. The $\mathrm{pH}$ of the test solutions was approximately 5.6. All of the test solutions were used under ambient conditions and room temperature (ca. $25^{\circ} \mathrm{C}$ ).

\subsection{Corrosion Experiments}

Potential distribution measurements, current distribution measurements, and galvanic current measurements were performed with the $\mathrm{Zn} /$ steel couples shown in Fig. 1. Each experimental procedure is explained in detail as follows.

\subsubsection{Potential Distribution Measurements}

Open circuit potentials (OCPs) were measured using a Type-A couple. The $\mathrm{Zn} /$ steel couple was placed in a glass vessel and the vessel was filled with the test solution. The surface of the test solution was over $1 \mathrm{~cm}$ above the surface of the couple. The OCP was measured with a commercial $\mathrm{Ag} / \mathrm{AgCl}$ electrode immersed in a saturated $\mathrm{KCl}$ solution $\left(\mathrm{SSE} ; E_{\mathrm{SSE}}=+0.197 \mathrm{~V}(\mathrm{SHE})\right.$ at $\left.25^{\circ} \mathrm{C}\right)$ connected to a Luggin capillary. The Luggin capillary used for the potential of the couple, a tapered glass rod with a tip diameter of less than $0.3 \mathrm{~mm}$. For the measurements of the average OCP of the couple, a Luggin capillary was fixed in the test solution far away from the couple. All of the potentials shown in this paper refer to this SSE.

Potential distributions on the $\mathrm{Zn} / \mathrm{steel}$ couples were measured using a scanning reference electrode technique (SRET) employed with a Type-A couple. The experimental setup was similar to that described above for the average OCP measurements, except that another Luggin capillary connected to the SSE was placed in the test solution $0.3 \mathrm{~mm}$ above the couple surface and scanned in 0.1-mm steps in the horizontal direction along $X$-axis at the center of $Y$-axis on the couple surface using PC-controlled stepping motors.

\subsubsection{Current Distribution Measurements}

Current distributions were measured using a scanning vibrating electrode technique (SVET) with a Type-B couple. The vibrating electrode was a Pt disk with a diameter of 20 $\mu \mathrm{m}$, and it was vibrated in the vertical direction at a frequency of $83 \mathrm{~Hz}$. The Pt disk electrode was placed $10 \mu \mathrm{m}$ above the surface of the zinc layer and scanned horizontally in 0.2$\mathrm{mm}$ steps along the surface of the couple using PC-controlled stepping motors. The amplitude of the potential variation measured at the vibrating Pt disk electrode against a reference Pt disk electrode was converted to a current density using a corresponding relationship obtained in preliminary experiments.

\subsubsection{Galvanic Current Measurement}

Galvanic currents between the zinc layer and the steel coupons were measured with a Type-C couple composed of four steel coupons with one of the four being coated with zinc and the remaining three being the same surface area. The galvanic current flowing from the zinc-coated steel coupon to each steel coupon was recorded with zero-resistance ammeters.

\section{Results and Discussion}

\subsection{OCP Transients}

Figure 2 shows OCP transients obtained with Type-A couples immersed in $\mathrm{NaCl}$ solutions. A similar trend is 
observed with all of the couples regardless of the solution concentration. Immediately after immersion, the OCP remains constant then, after a certain period of time, shifts to a maximum value and then gradually declines. At this point, red iron rust was observed on the couple.

Based on the behavior shown in Fig. 2, the OCP transients could be divided roughly into two stages. Stage I is the period during which the OCP is constant near the corrosion potential of zinc. Stage II describes the rise in OCP up to a positive potential and the gradual decay with prolonged immersion time. The OCP value in Stage I indicates the sacrificial dissolution of the zinc layer, which prevents the remaining steel from corroding. At higher $\mathrm{NaCl}$ concentrations, the duration of Stage I decreases and the OCP decreases to more negative potentials. These results indicate

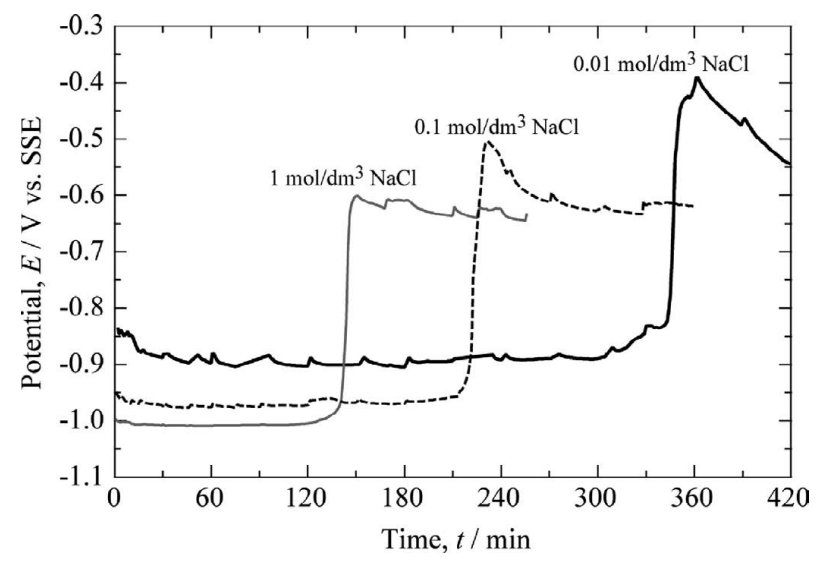

Fig. 2. Transients of corrosion potential of Type-A couples immersed in various concentrations of $\mathrm{NaCl}$. that the anodic dissolution of zinc becomes accelerated in higher concentrations of $\mathrm{NaCl}$. Conversely, in Stage II, the sacrificial zinc layer is extinct and steel corrosion begins at the couple surface. In the following sections, the corrosion behavior of a $\mathrm{Zn} / \mathrm{steel}$ couple in Stages I and II will be discussed in detail.

\subsection{Corrosion Behavior in Stage I}

3.2.1. Potential Distribution and Surface Morphology

Figures 3(a)-3(c) show the horizontal potential distributions for a Type-A couple measured 60 min after immersion in various $\mathrm{NaCl}$ solutions. Figure 3(a) shows that potentials on the zinc layer are more negative than those on the steel surface, and that the potentials increase to more positive values with increasing distance from the zinc layer. However, potentials measured far from the zinc surface, even those on the steel surface, are much less than the standard potential of iron $\left(E^{0}\left(\mathrm{Fe}^{2+} / \mathrm{Fe}\right)=-0.64 \mathrm{~V}\right.$ vs. SSE $)$. This indicates that the whole-steel surface is polarized to a cathodic potential sufficient to prevent steel corrosion. In addition, the potential distribution as a whole shifts to more negative values with increasing $\mathrm{NaCl}$ concentration, which is the same trend as that observed with the OCP values in Stage I. Note, however, that the horizontal variation in the potential distribution profiles across the couple becomes smaller with increasing $\mathrm{NaCl}$ concentration due to the increasing conductivity of the solution. Furthermore, potentials on the zinc layer and on the remaining steel surface do not change greatly throughout Stage I. These results indicate that in Stage I, the zinc layer and the steel always work as anode and cathode, respectively.

Figures 3(d)-3(f) show the absolute gradients of potential
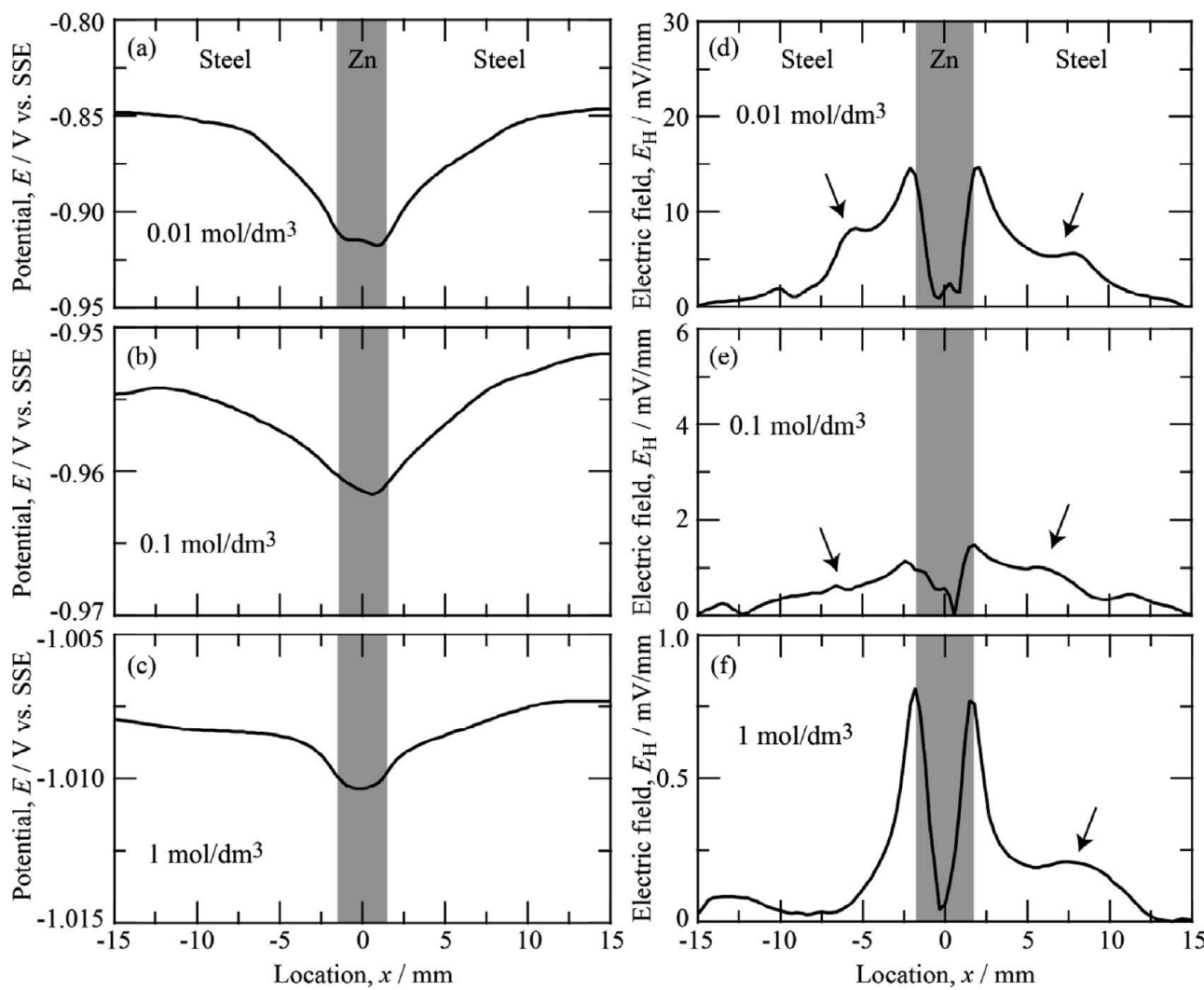

Fig. 3. Potential distributions and $E_{\mathrm{H}}$ for Type-A couples after $60 \mathrm{~min}$ immersion in various concentrations of $\mathrm{NaCl}$ : (a) and (d) $0.01 \mathrm{~mol} / \mathrm{dm}^{3},(b)$ and (e) $0.1 \mathrm{~mol} / \mathrm{dm}^{3}$, and (c) and (f) $1 \mathrm{~mol} / \mathrm{dm}^{3}$. 
along the horizontal direction, $E_{\mathrm{H}}$, obtained from the potential distributions in Fig. 3(a)-3(c). The $E_{\mathrm{H}}$ distributions have similar implications with the current flow along the horizontal direction between the zinc layer and the steel surface on a $\mathrm{Zn} /$ steel couple. Plots of $E_{\mathrm{H}}$ show peaks at the edges of the zinc layer in all cases, indicating that the current along the horizontal direction reaches a maximum at the $\mathrm{Zn} / \mathrm{steel}$ interface because the zinc and steel act as anode and cathode, respectively. In addition, $E_{\mathrm{H}}$ values are relatively small near the center of the zinc layer, suggesting that the vertical components, rather than the horizontal components, of the current vector are dominant on the zinc layer. In contrast, on the steel surface, $E_{\mathrm{H}}$ decreases gradually with increasing distance from the zinc layer in all cases. The $E_{\mathrm{H}}$ distributions also exhibit shoulders, indicated by arrows, at the steel surface a certain distance away from the zinc layer, suggesting that the current flow along the horizontal direction is not uniform on the steel surface at these points.

The surface morphology of the Type-A couple was examined to elucidate the source of these shoulders. Figure 4 shows the surface of a Type-A couple after $60 \mathrm{~min}$ in $\mathrm{NaCl}$ solutions of various concentrations. The corrosion products of zinc can be seen as white areas on the steel surface. As the locations of these white areas correlate with the locations of the shoulders in the $E_{\mathrm{H}}$ distributions, the precipitation of zinc corrosion products seems to affect the current flow from the zinc layer to the steel surface.

Furthermore, as shown in Fig. 4, the precipitation morphology of the zinc corrosion products depends on the $\mathrm{NaCl}$

(a)

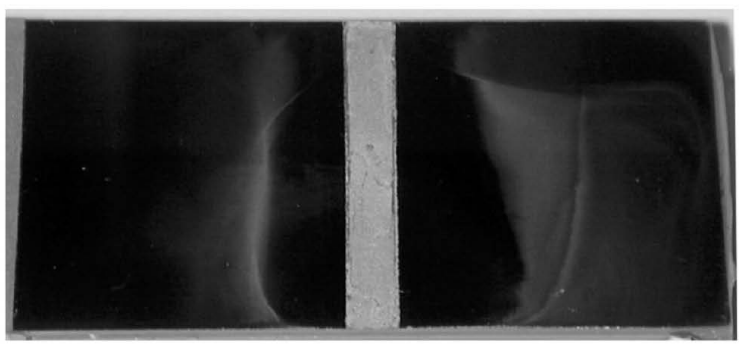

(b)

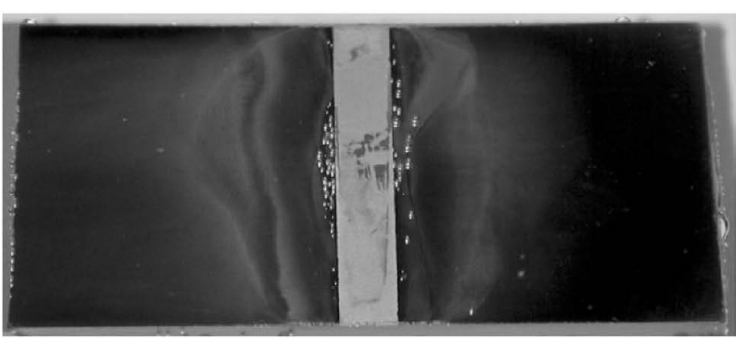

(c)

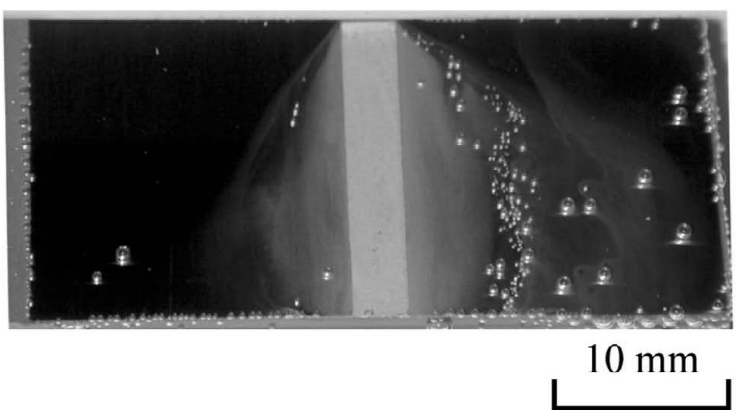

Fig. 4. Surface morphology of Type-A couples after 60 min immersion in various concentrations of $\mathrm{NaCl}$ : (a) $0.01 \mathrm{~mol} / \mathrm{dm}^{3}$, (b) $0.1 \mathrm{~mol} / \mathrm{dm}^{3}$, and (c) $1 \mathrm{~mol} / \mathrm{dm}^{3}$. concentration. In $0.01 \mathrm{~mol} / \mathrm{dm}^{3} \mathrm{NaCl}$, the zinc corrosion products were only observed on the steel surface at a certain distance away from the zinc layer. In higher concentrations of $\mathrm{NaCl}$, the zinc corrosion products were formed immediately around the zinc layer, as shown in Figs. 4(b) and 4(c). These results suggest that the ionic distributions of $\mathrm{OH}^{-}$and $\mathrm{Zn}^{2+}$ above the couple surface depend on the $\mathrm{NaCl}$ concentration because precipitation of zinc corrosion products is associated with the solution products of the concentrations of $\mathrm{Zn}^{2+}$ and $\mathrm{OH}^{-}$. Both the potential distributions and surface morphologies of the couples indicate that the precipitation of zinc corrosion products and its dependence on $\mathrm{NaCl}$ concentration are associated with the electrochemical reactivity of the couple surface.

\subsubsection{Galvanic Corrosion Process}

The anodic, sacrificial dissolution of zinc takes place by the following reaction.

$$
\mathrm{Zn} \longrightarrow \mathrm{Zn}^{2+}+2 \mathrm{e}^{-}
$$

The corresponding cathodic reaction is the reduction of dissolved oxygen (an oxygen reduction reaction, or ORR) in the $\mathrm{NaCl}$ solution and is generally considered to take place on the couple surface as follows.

$$
\frac{1}{2} \mathrm{O}_{2}+\mathrm{H}_{2} \mathrm{O}+2 \mathrm{e}^{-} \longrightarrow 2 \mathrm{OH}^{-}
$$

However, as shown in Figs. 3(a)-3(c), the potentials of the steel surface depend on the $\mathrm{NaCl}$ concentration of the surrounding solution. For example, in $0.01 \mathrm{~mol} / \mathrm{dm}^{3} \mathrm{NaCl}$, this surface potential ranges from -0.9 to $-0.85 \mathrm{~V}$, and in 0.1 $\mathrm{mol} / \mathrm{dm}^{3}$ and $1 \mathrm{~mol} / \mathrm{dm}^{3} \mathrm{NaCl}$, the surface potential is less than $-0.95 \mathrm{~V}$. This suggests that different cathodic reactions can take place on the steel surface depending on the $\mathrm{NaCl}$ concentration. This effect is due to the large cathodic polarization and can cause the consequent enhancement of the hydrogen evolution reaction (HER) through the dissociation of water. Therefore, cathodic polarization curves for steel were measured in various $\mathrm{NaCl}$ solutions. As shown in Fig. $\mathbf{5}$, the cathodic behavior of steel is almost independent of the $\mathrm{NaCl}$ concentration. On the cathodic polarization curves, the

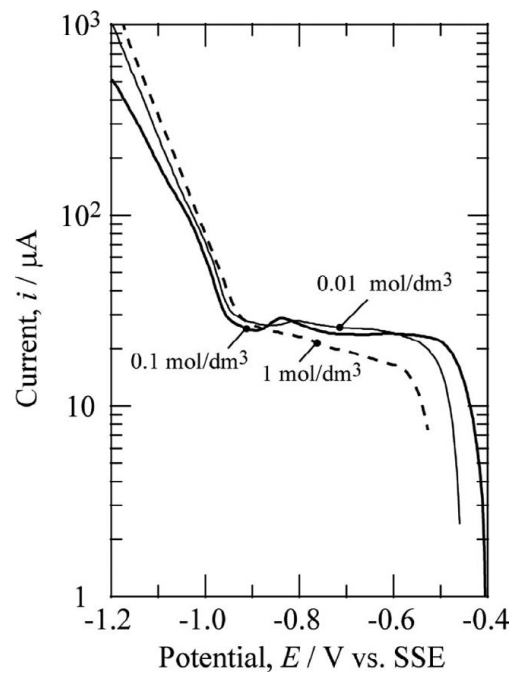

Fig. 5. Cathodic polarization curves for steels in various concentrations of $\mathrm{NaCl}$ 
diffusion-limiting current of the ORR can be observed in potential regions more positive than $-0.95 \mathrm{~V}$. In contrast, in potential regions less than $-0.95 \mathrm{~V}$, an increase in cathodic current is observed due to the HER, as shown below.

$$
2 \mathrm{H}_{2} \mathrm{O}+2 \mathrm{e}^{-} \longrightarrow \mathrm{H}_{2}+2 \mathrm{OH}^{-}
$$

According to the cathodic polarization curves in Fig. 5 and the potential distributions in Fig. 3(a), the dominant cathodic reaction on the couple in $0.01 \mathrm{~mol} / \mathrm{dm}^{3} \mathrm{NaCl}$ is an ORR. In solutions containing more than $0.01 \mathrm{~mol} / \mathrm{dm}^{3} \mathrm{NaCl}$, the HER can be evolved in addition to ORR on the couple surface although the HER occurs primarily on the steel surface because the HER is sluggish on zinc. ${ }^{9)}$ This can be confirmed from the results that bubbles of $\mathrm{H}_{2}$ are observed on the steel surface according to Eq. (3) in higher concentrations of $\mathrm{NaCl}$ as shown in Figs. 4(b) and 4(c). In addition, the surface potentials in Figs. 3(b) and 3(c), and the potentials of the zinc layer, decrease to negative potentials with increasing $\mathrm{NaCl}$ concentration. Therefore, it can be said that the decreases in the surface potential of the zinc layer can polarize the steel surface to sufficiently negative potentials to accelerate the HER.

Changes in the cathodic reaction on the steel surface should be related to the precipitation morphology of zinc corrosion products because of the changes in $\mathrm{OH}^{-}$distribution above the surface of the $\mathrm{Zn} /$ steel couple. Previous studies have shown that zinc corrosion products form on the steel a certain distance away from the zinc layer, as shown in Fig. 4(a). ${ }^{6-8)}$ These studies have also shown that a region of lower $\mathrm{pH}$ is formed on the steel surface around the zinc layer. This is because $\mathrm{Zn}^{2+}$ ions evolved from the zinc layer react with $\mathrm{OH}^{-}$ions evolved by the ORR, forming $\mathrm{ZnOH}^{+}$ as follows.

$$
\mathrm{Zn}^{2+}+\mathrm{OH}^{-} \longrightarrow \mathrm{ZnOH}^{+}
$$

Therefore, a $\mathrm{pH}$ increase on the steel surface around the zinc layer can be suppressed according to Eq. (4), thereby preventing the deposition of zinc corrosion products in that area.

However, Figs. 4(b) and 4(c) show that zinc corrosion products were precipitated on the steel surface near the zinc layer, which are different from the precipitation morphology observed in $0.01 \mathrm{~mol} / \mathrm{dm}^{3} \mathrm{NaCl}$. This change in the precipitation morphology is attributable to the formation of a high $\mathrm{pH}$ region near the zinc layer. As noted above, in high-concentration $\mathrm{NaCl}$ solutions, a HER can occur simultaneously with an ORR. When a HER is enhanced, larger amounts of $\mathrm{OH}^{-}$ions can be evolved based on Eq. (3), resulting in the formation of a region with higher $\mathrm{OH}^{-}$concentration. Under these conditions, $\mathrm{Zn}^{2+}$ ions emitted by anodic dissolution of the zinc layer are transported into the high $\mathrm{pH}$ region by mass transport and react with $\mathrm{OH}^{-}$to form zinc corrosion products via the following reaction.

$$
\mathrm{Zn}^{2+}+2 \mathrm{OH}^{-} \longrightarrow \mathrm{Zn}(\mathrm{OH})_{2}
$$

In this case, since the $\mathrm{OH}^{-}$concentration is relatively high, the buffer action of $\mathrm{Zn}^{2+}$ to suppress the $\mathrm{pH}$ increase should be insufficient. Therefore, in more concentrated $\mathrm{NaCl}$ solutions, the $\mathrm{pH}$ increase can be inevitable at the steel surface around the zinc layer due to an enhancement in the HER. Consequently, the zinc corrosion products precipitate in the corresponding area.

\subsubsection{The Effect of Precipitation of Zinc Corrosion Prod- ucts}

As shown above, zinc corrosion products are formed on the surface of the couple during galvanic corrosion. SVETs were employed to measure current distributions on Type-B couples immersed in $0.01 \mathrm{~mol} / \mathrm{dm}^{3} \mathrm{NaCl}$ to determine whether these zinc corrosion products affect the rate of electrochemical reactions on the $\mathrm{Zn} /$ steel couple.

Figure 6 shows changes in the current distribution on the $\mathrm{Zn}$ /steel couple during Stage I. As shown in Figs. 6(a) and 6(b), higher anodic current density is observed at the edges of the zinc layer. Although the current density measured by the SVET reflects the current flow in the vertical direction to the couple surface, the profiles in Figs. 6(a) and 6(b) are quite similar to the $E_{\mathrm{H}}$ curve in Fig. 3 . In addition, the regions of higher anodic current shift to the center of the zinc layer with increasing immersion time (Fig. 6(c)). These results indicate that the anodic dissolution of zinc is accelerated dominantly at the edges of the zinc layer.

The current density on the steel surface is relatively low and confirming whether the zinc corrosion products affect the rate of electrochemical reaction is difficult. However, small responses are observed in the SVET profiles of the steel surface, denoted by arrows in Fig. 6, where zinc corrosion products are formed (Fig. 6(d)). These responses are associated with the shoulders seen in the potential distribution profiles in Fig. 3(d).

Galvanic currents were also measured between the zinc and steel with Type- $\mathrm{C}$ couples in $\mathrm{NaCl}$ solutions of various concentrations. Galvanic currents are produced by anodic dissolution of the zinc layer and delivered to each steel coupon depending on its distance from the zinc layer, surface

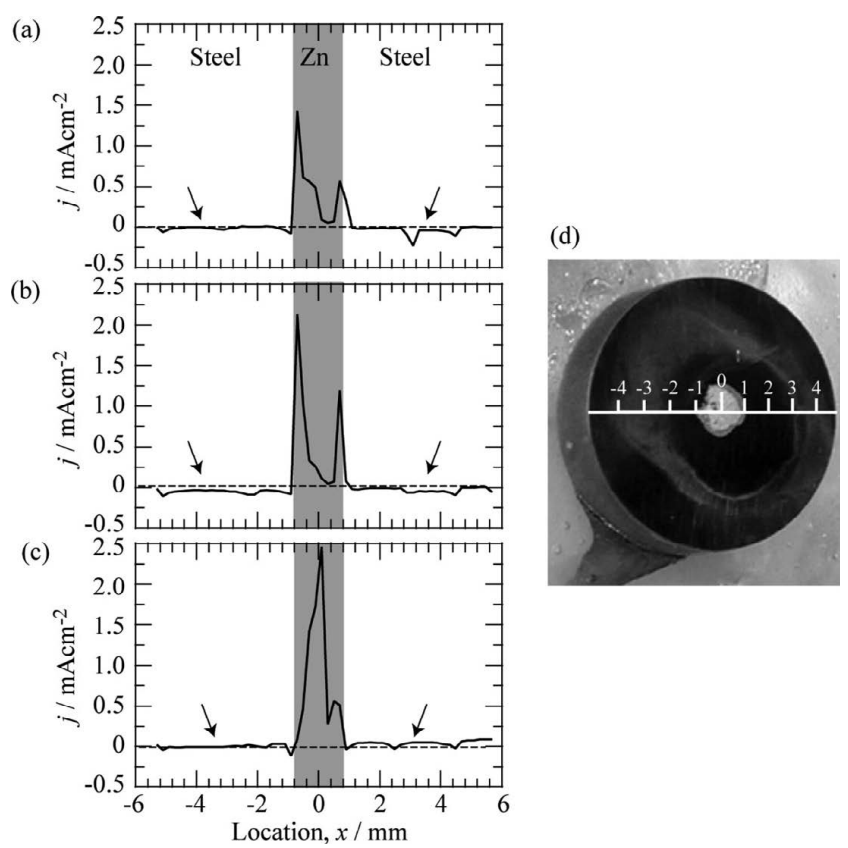

Fig. 6. Change in current distributions of a Type-B couple measured during galvanic corrosion of the zinc layer in 0.01 $\mathrm{mol} / \mathrm{dm}^{3} \mathrm{NaCl}$ : (a) $40 \mathrm{~min}$, (b) $65 \mathrm{~min}$, and (c) $80 \mathrm{~min}$. The photograph (d) shows the surface morphology of the couple taken at 105 min after immersion. 


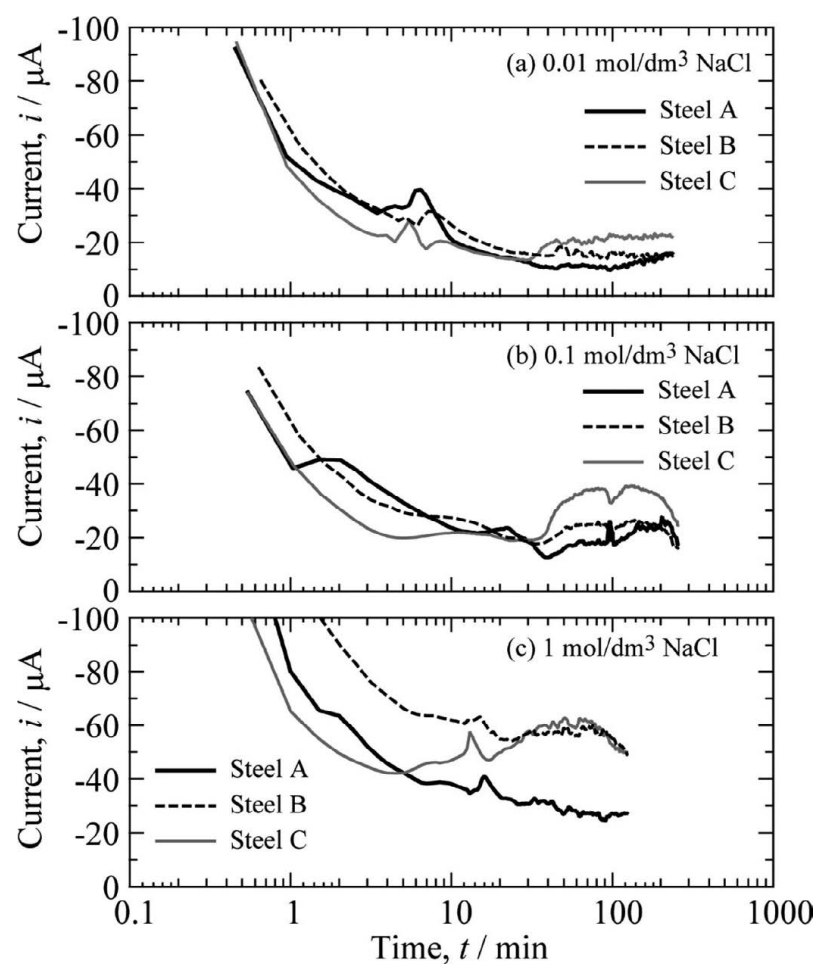

Fig. 7. Transients of galvanic current flowing into each steel coupon for type $\mathrm{C}$ couples immersed in various concentrations of $\mathrm{NaCl}$ : (a) $0.01 \mathrm{~mol} / \mathrm{dm}^{3}$, (b) $0.1 \mathrm{~mol} / \mathrm{dm}^{3}$, and (c) $1 \mathrm{~mol} / \mathrm{dm}^{3}$.

reactivity, and other associated factors. In particular, since zinc corrosion products precipitate onto the steel surface during galvanic corrosion of the $\mathrm{Zn} /$ steel couple, the magnitude of the galvanic current depends on the electrochemical reactivity of the underlying steel surface.

Figure 7 shows transients of the galvanic current flowing between the zinc layer and three steel coupons. In addition, Fig. 8 illustrates the precipitation morphology of the zinc corrosion products on the $\mathrm{Zn} /$ steel couple measured simultaneously with the galvanic current. The data in Fig. 7 indicate that all of the galvanic currents flowing from the zinc layer to each steel coupon decay with immersion time while the magnitude of the galvanic current on each steel coupon is unique. Note that, in all cases, the galvanic current flowing from the zinc layer to the nearest steel coupon (Steel A in Fig. 3(c)) is the lowest among the three steel coupons. At this time, zinc corrosion products are formed primarily on the steel coupon nearest the zinc layer, as shown in Fig. 8. Furthermore, as in Figs. 4(b) and 4(c), Figs. 8(b) and 8(c) show the evolution of $\mathrm{H}_{2}$ bubbles by the HER on the steel surfaces, mainly along the edges of zinc corrosion products (Fig. 4(c)) but not on the corrosion products themselves. These results indicate that the precipitation of zinc corrosion products inhibits the cathodic reaction both of the ORR and HER on the steel surface. Several researchers have reported, based on SVETs, that cathodic reactions such as the ORR and HER are inhibited by the precipitation of zinc-based corrosion products. ${ }^{10-13)}$ The results obtained herein agree well with those reports. In addition, Yadav et al. measured cathodic polarization curves for zinc with and without zinc corrosion products using a rotating ring disk electrode and reported the inhibition of ORR by the precipitation of zinc corrosion products. ${ }^{14)}$ These results suggest that the shoul- (a)

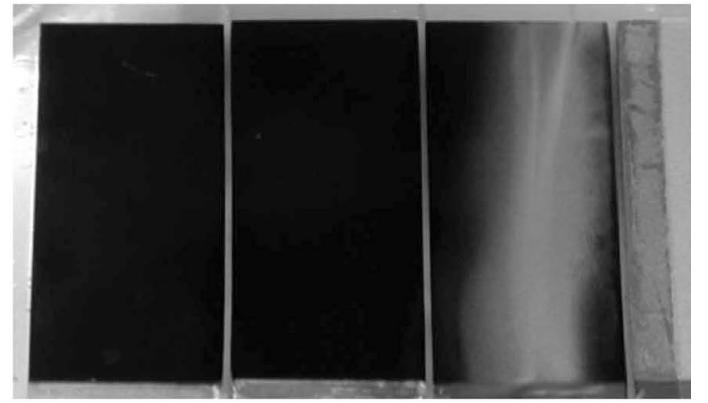

(b)

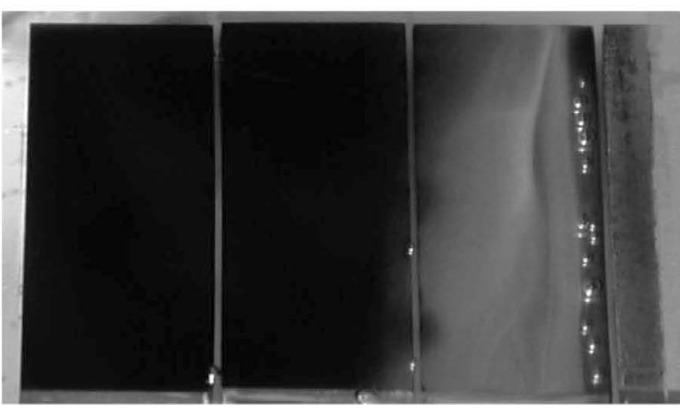

(c)

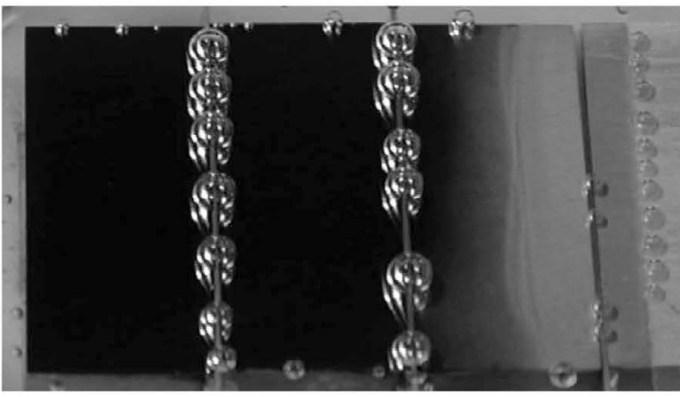

$5 \mathrm{~mm}$

Fig. 8. Surface morphology of Type-C couples after immersion in various concentrations of $\mathrm{NaCl}$ : (a) $0.01 \mathrm{~mol} / \mathrm{dm}^{3}$, (b) 0.1 $\mathrm{mol} / \mathrm{dm}^{3}$, and (c) $1 \mathrm{~mol} / \mathrm{dm}^{3}$.

ders observed in the $E_{\mathrm{H}}$ distributions in Figs. 3(d)-3(f) at the steel surface are due to a heterogeneous distribution of the cathodic current caused by the zinc corrosion products.

\subsubsection{Galvanic Corrosion Rate of a $\mathrm{Zn} / \mathrm{steel}$ Couple}

In aqueous solutions of neutral $\mathrm{pH}$, the dissolution rate of the zinc layer is determined by the cathodic reaction rate on the $\mathrm{Zn} /$ steel couple and the anodic polarization behavior of zinc, which exhibits a small Tafel slope. That is, the galvanic corrosion rate of the $\mathrm{Zn} / \mathrm{steel}$ couple is controlled by the magnitude of the cathodic reaction. As discussed in section 3.2.2, the cathodic reaction(s) taking place on the couple can be an ORR, or a combination of an ORR and HER depending on the potential of the zinc layer. Therefore, the potential of the zinc layer is one of the most important factors in determining the galvanic corrosion rate of the $\mathrm{Zn} / \mathrm{steel}$ couple. As shown in Fig. 9, anodic polarization curves for zinc shift with an increasing $\mathrm{NaCl}$ concentration. This shift can induce a change in the cathodic reaction on the steel surface from an ORR alone to both an ORR and HER. Thus, the corrosion potential of zinc in aqueous solutions has a major impact on the galvanic corrosion rate of $\mathrm{Zn} / \mathrm{steel}$ couples.

The current study has demonstrated that the precipitation of zinc corrosion products can inhibit both an ORR and 


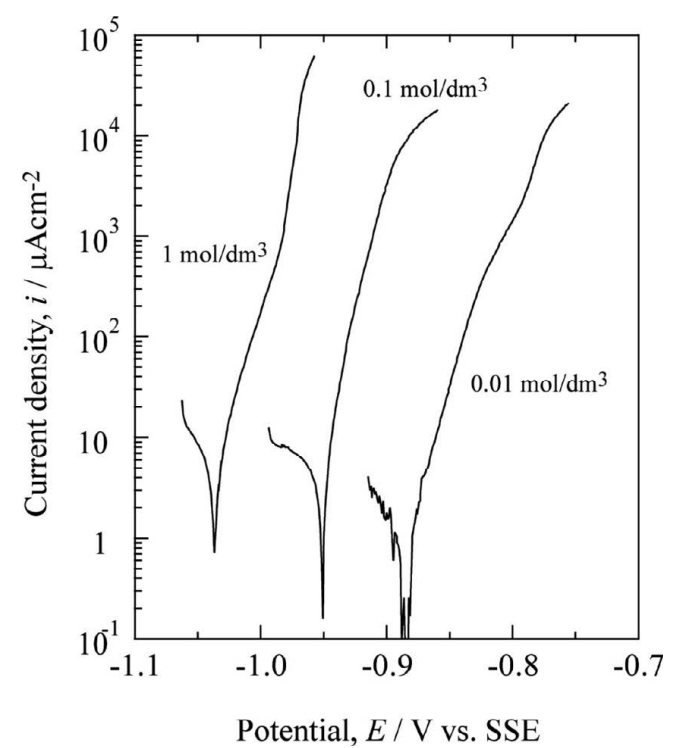

Fig. 9. Anodic polarization curves for zinc in various concentration of $\mathrm{NaCl}$.
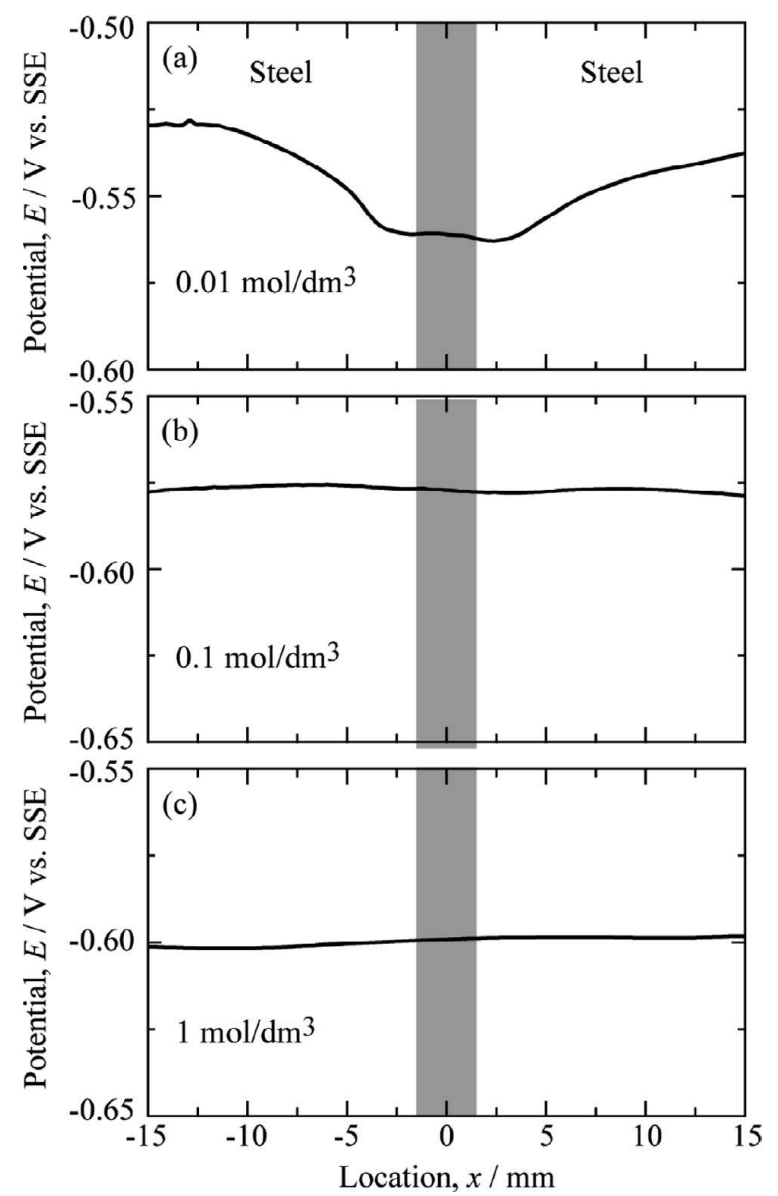

Fig. 10. Potential distributions for Type-A couples measured in Stage II in various concentrations of $\mathrm{NaCl}$ : (a) $0.01 \mathrm{~mol} / \mathrm{dm}^{3}$, (b) $0.1 \mathrm{~mol} / \mathrm{dm}^{3}$, and (c) $1 \mathrm{~mol} / \mathrm{dm}^{3}$.

HER on the underlying steels. This means that the precipitation of zinc corrosion products may be related to the galvanic corrosion rate of $\mathrm{Zn} /$ steel couples because cathodic reaction rate can be decreased with the progress of the precipitation of zinc corrosion products. Therefore, it is necessary to investigate how the reactivity of the cathodic reac- (a)

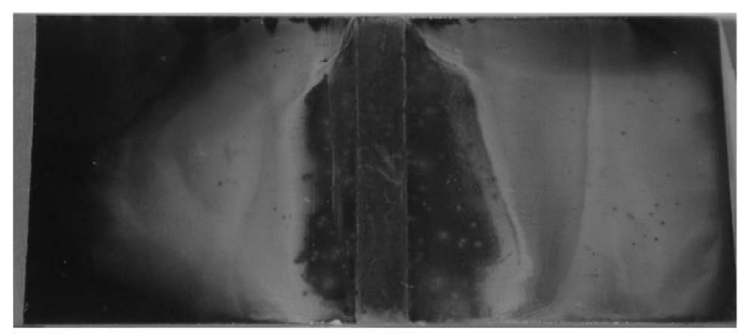

(b)

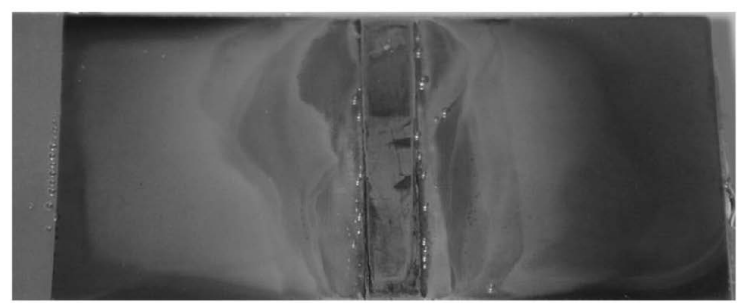

(c)

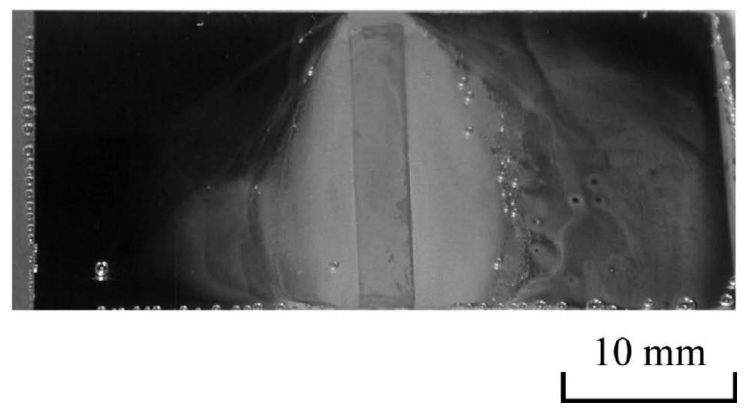

Fig. 11. Surface morphology of Type-C couples taken in Stage II in various concentrations of $\mathrm{NaCl}$ : (a) $0.01 \mathrm{~mol} / \mathrm{dm}^{3}, 360$ min, (b) $0.1 \mathrm{~mol} / \mathrm{dm}^{3}, 300 \mathrm{~min}$, and (c) $1 \mathrm{~mol} / \mathrm{dm}^{3}, 210$ $\min$.

tion at the steel surface under the zinc corrosion products can be inhibited. This issue is now under investigation.

\subsection{Steel Corrosion in Stage II}

After the extinction of sacrificial zinc, Stage II starts with an abrupt jump and gradual decrease in the OCP transient, indicating the onset of steel corrosion. To locate the position of the onset of steel corrosion in Stage II, horizontal potential distributions were measured on Type-A couples immersed in $\mathrm{NaCl}$ solutions as shown in Fig. 10. Photographs of the $\mathrm{Zn} /$ steel couples were taken simultaneously with these measurements (Fig. 11). In Fig. 10(a), the potentials near the center of the couple surface where the zinc layer had been are more negative than those far from the center of the couple. At this point, iron rusts are observed in the locations with lower potentials, as shown in Fig. 11(a). Furthermore, SVET experiments during Stage II with Type-B couples in $0.01 \mathrm{~mol} / \mathrm{dm}^{3} \mathrm{NaCl}$ yield higher anodic current densities near the location where the zinc layer had been (Figs. 12(a) and 12(b)). Figure 12(c) shows that these regions correspond to the location of iron rusts.

In contrast, the data in Figs. 10(b) and 10(c) show that potential distributions in solutions containing greater than $0.01 \mathrm{~mol} / \mathrm{dm}^{3} \mathrm{NaCl}$ do not provide clear evidence as to the onset location of steel corrosion. This may be due to higher electric conductivity with $\mathrm{NaCl}$ concentration. As shown in Figs. 11(b) and 11(c), steel corrosion can be already observed on the couple surface. Then the galvanic currents were measured with the couple (inset in Fig. 13(b)) similar to Type $\mathrm{C}$ in Fig. 1. As shown in Fig. 13, the galvanic cur- 
(a)

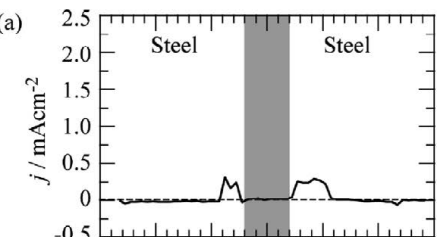

(b)

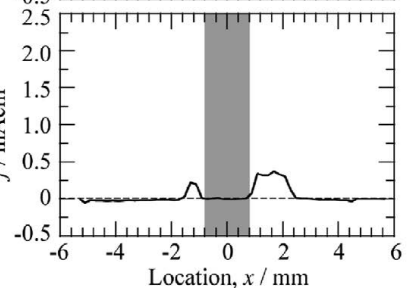

(c)

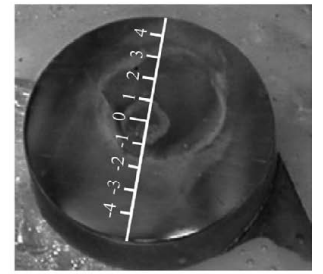

Fig. 12. Change in current distributions ((a) and (b)) and surface morphology (c) obtained in $0.01 \mathrm{~mol} / \mathrm{dm}^{3}$ in Stage II: (a) $173 \mathrm{~min}$, (b) $210 \mathrm{~min}$, and (c) $210 \mathrm{~min}$.
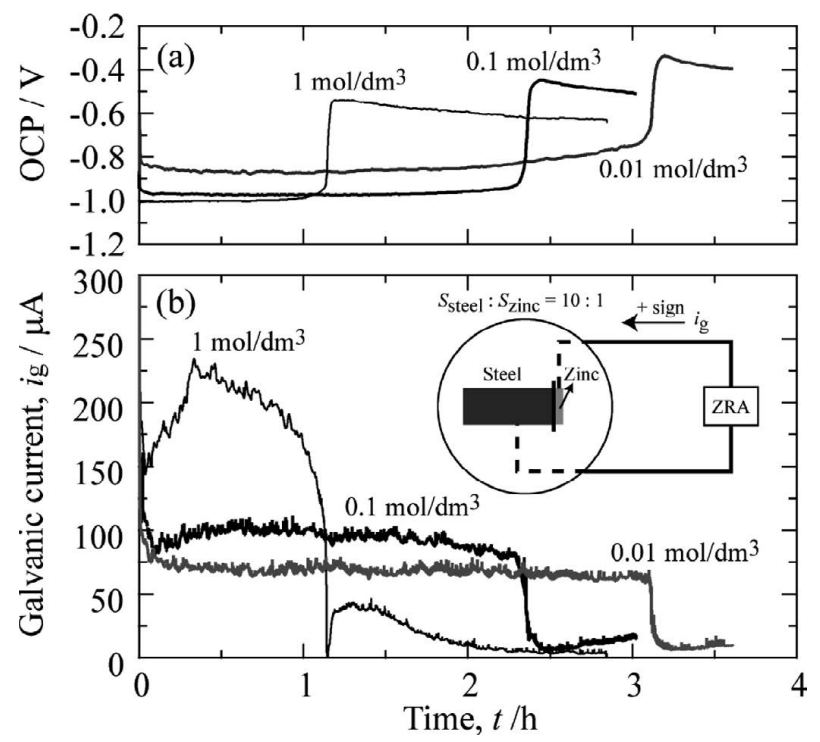

Fig. 13. Transients of (a) OCP and (b) galvanic currents for TypeC couples immersed in various concentrations of $\mathrm{NaCl}$ : (a) $0.01 \mathrm{~mol} / \mathrm{dm}^{3}$, (b) $0.1 \mathrm{~mol} / \mathrm{dm}^{3}$, and (c) $1 \mathrm{~mol} / \mathrm{dm}^{3}$.

rents measured in various $\mathrm{NaCl}$ concentrations are all positive in Stage II, indicating that the steel coupon that had been coated with zinc still behaves as an anode in the early part of Stage II.

The above discussion implies that the location of the onset of steel corrosion may depend on the solution chemistry just after the extinction of the sacrificial zinc. In particular, in $0.01 \mathrm{~mol} / \mathrm{dm}^{3} \mathrm{NaCl}$, distinct $\mathrm{pH}$ distributions formed on the couple surface through the combination of an ORR and the hydrolysis reaction of $\mathrm{Zn}^{2+}$ ions. High-pH regions formed on the steel far from the zinc layer, thereby passivating these regions. Therefore, steel corrosion can be favored in the low-pH region around the center of the $\mathrm{Zn} /$ steel couple. This is in good agreement with the surface observation results in Fig. 11(a). In solutions with greater than $0.01 \mathrm{~mol} / \mathrm{dm}^{3} \mathrm{NaCl}, \mathrm{pH}$ values over the entire steel surface may increase due to the evolution of the HER. This was confirmed by the precipitation morphology of the zinc corrosion products. Therefore, just after the extinction of galvanic action, steel corrosion begins rather around the steel surface where the zinc layer had been.

\section{Conclusion}

In this study, the corrosion behavior of a model $\mathrm{Zn} / \mathrm{steel}$ couple was investigated in aqueous $\mathrm{NaCl}$ solutions by measuring potential and current distributions and details of local electrochemical and chemical reactions during galvanic corrosion of the couple were discussed. The following findings were obtained.

(1) From the results of potential and current distributions, the zinc layer and the steel worked as anode and cathode, respectively, during Stage I.

(2) In Stage I, the precipitation morphology of the zinc corrosion products depended on the concentration of aqueous $\mathrm{NaCl}$. In addition, the morphology of zinc corrosion precipitate was explained by changes in the dominant cathodic reaction on the steel surface, and the reactivity of the cathodic reaction on the underlying steel surface was suppressed by the presence of the zinc corrosion products.

(3) Stage II represents the onset of steel corrosion, whose location was related to the $\mathrm{pH}$ distribution on the couple just prior to the extinction of sacrificial zinc.

\section{REFERENCES}

1) A. Andoh, J. Uchida, H. Entani, C. Kato, H. Kuroda T. Satou, M. Shimizu, S. Fujita, A. Miyasaka, Y. Morimoto and M. Yamashita: Tetsu-to-Hagané, 89 (2003), 3.

2) X. G. Zhang: Corrosion and Electrochemistry of Zinc, Plenum Press, New York, (1996), 261.

3) X. G. Zhang: J. Electrochem. Soc., 143 (1996), 1472.

4) M. Matsumoto: J. Surf. Finish. Soc. Jpn., 57 (2006), 25.

5) S. Fujita and D. Mizuno: Corros. Sci., 49 (2007), 211.

6) E. Tada, K. Sugawara and H. Kaneko: Electrochim. Acta, 49 (2004), 1019 .

7) E. Tada and H. Kaneko: Corros. Sci., 52 (2010), 3421

8) E. Tada, S. Satoh and H. Kaneko: Electrochim. Acta, 49 (2004), 2279 .

9) H. Kita: J. Electrochem. Soc., 113 (1966), 1095.

10) K. Ogle, V. Baudu, L. Garrigues and X. Philippe: J. Electrochem. Soc., 147 (2000), 3654.

11) F. Thébault, B. Vuillemin, R. Oltra, K. Ogle and C. Alley: Electrochim. Acta, 53 (2008), 5226.

12) F. Thébault, B. Vuillemin, R. Oltra, C. Allely, K. Ogle and E. Tada: ECS Trans., 11 (2008), 91.

13) K. Ogle, S. Morel and D. Jaquet: J. Electrochem. Soc., 153 (2006), 1

14) A. P. Yadav, A. Nishikata and T. Tsuru: J. Electroanal. Chem., 585 (2005), 142. 